\title{
Estimating Earth's Surface Deformation from GPS and DInSAR Data Integration
}

\section{A. Saad, A. Elshehaby, Mervat M. Refaat, and R. Fekry}

Surveying Engineering Department, Benha University, Cairo, Egypt.

Corresponding Author: Mervat M. Refaat, Surveying Engineering Department, Benha University, Cairo, Egypt.

E-mail: mervat_mohamed@cic-cairo.com

Received date: 11 March 2018, Accepted date: 15 June 2018, Online date: 20 June 2018

Copyright: (C) 2018 Mervat M. Refaat, et al. This is an open-access article distributed under the terms of the Creative Commons Attribution License, which permits unrestricted use, distribution, and reproduction in any medium, provided the original author and source are credited.

\begin{abstract}
Integration of ground and space geodetic datasets to monitor the surface deformation has become an effective and important way to take the advantages of both techniques in such studies. Global Positioning System (GPS) calculates the crustal movement in $3 \mathrm{D}$ space at the receiver location. On the other hand, Differential Synthetic Aperture Radar (DInSAR) can measure the change in the measured range along the radar Line of Sight (LOS) in millimeters level of accuracy with high spatial resolution. In this research, GPS measurements and DInSAR data have been used simultaneously to monitor the crustal movement in Aswan south of Egypt. ENVISAT ASAR descending orbit data and GPS observations of Aswan geodetic network from 2008 to 2010 was integrated via SISTEM algorithm. The results of GPS and DInSAR integration show an average motion of $30 \pm 4.4 \mathrm{~mm}, 54.8 \pm 27.5,45.2 \pm 11.9 \mathrm{~mm}$ in East, North and Vertical directions respectively. The accuracy of GPS and DInSAR data integration is checked using three permanent GPS stations whereas the mean differences at the three stations are $3.6 \pm 2.2,1.9 \pm 1.6$ and $8.2 \pm 4.5 \mathrm{~mm}$ in $\mathrm{x}, \mathrm{y}$ and $\mathrm{z}$ directions respectively.
\end{abstract}

Key words: GPS; ASAR; DInSAR; SISTEM Integration; crustal displacement; deformation monitoring.

\section{INTRODUCTION}

InSAR and GPS have been simultaneously used for Tensor Estimation from satellite and geodetic deformation Measurements" is used to derive the threedimensional displacement maps from DInSAR deformation monitoring according to their complementary nature as InSAR measures the terrain displacement along the radar Line of Sight (LOS) in sub-centimeter level of accuracy (Perski 2000; Ge et al. 2003) with high spatial resolution relying on the swath width of the radar mode and low temporal resolution depending upon the satellite revisit time (Samsonov et al., 2006). On the other hand, GPS investigates the threedimensional position displace-ments in sub-centimeter level (Shaker, A. et al., 2010) by comparing the receiver coordinates for two or sequential time epochs (high temporal resolution).

The new technique SISTEM (Guglielmino et al., 2011) stands for "Simultaneous and Integrated Strain LOS displacements and 3D position displacements from GPS measurements. SISTEM is based on the elastic theory assuming a geodynamic process deforms a part of the Earth's surface under the small deformation and strain theory such that an despotic point $P$, had contained $x_{0}=\left(x_{10}, x_{20}, x_{30}\right)$, and $N$ surrounding experimental points (EPs) whose placement and extirpation are respectively $\boldsymbol{x}_{(n)}=\left(x_{I(n)}, x_{2(n)}, x_{3(n)}\right)$ and $\boldsymbol{u}_{(n)}=\left(u_{1(n)}, u_{2(n)}, u_{3(n)}\right)$ where $n=1 \ldots N$.

Is a such postulate, take on a linear program, the problem of valuable of the displacement components $U i(\mathrm{i}=1 \ldots 3)$ of the point $P$, from the experimental results $\boldsymbol{u}_{(n)}=\left(u 1_{(n)}, u 2_{(n)}, u 3_{(n)}\right)$, can be patterned by the $\mathrm{N}$ equations:

$\mathrm{u}_{\mathrm{i}(\mathrm{n})}=\mathrm{H}_{\mathrm{ij}} \times \Delta \mathrm{X}+\mathrm{U}_{\mathrm{i}} \quad(\mathrm{i}, \mathrm{j}=1 \ldots 3)$

Where $\mathrm{x}_{\mathrm{j}(\mathrm{n})}=\mathrm{x}_{\mathrm{j}(\mathrm{n})}-\mathrm{x}_{\mathrm{j} 0}$ are proportional position of the $\mathrm{n}^{\text {th }}(\mathrm{EP})$ experimental points and the arbitrary point $\mathrm{P}$ and,

$H$ iij $=\frac{2 u i}{2 x i}$

These equation $\mathrm{H}=\mathrm{E}+\Omega$, showed that the elements of the displacement gradient tensor had been in symmetric and antisymmetric part, where $\mathrm{E}$ is the strain tensor and $\Omega$ is the rigid body rotation tensor.

A DInSAR interferogram may be able to be connected with the unknown components $\mathrm{Ui}(\mathrm{i}=1 \ldots 3)$ of the displacement vector of the point $\mathrm{P}$ approve to the equation:

$\mathrm{D}^{\mathrm{P}}{ }_{\mathrm{LOS}}=\left[\mathrm{U}_{1} \mathrm{U}_{2} \mathrm{U}_{3}\right] .\left[\mathrm{S}_{\mathrm{x}} \mathrm{S}_{\mathrm{y}} \mathrm{S}_{\mathrm{z}}\right]^{\mathrm{T}}$

Where,

$\mathrm{D}_{\text {LOS }}^{\mathrm{P}}$ is the LOS displacements, at the point $\mathrm{P}$ on the Earth's surface. Whereas, $\mathrm{S}=[\mathrm{Sx}$ Sy Sz] is a unit vector pointing from the point $\mathrm{P}$ toward the satellite and it could be written as compact form on the method of equations (1 and 3) as following:

$A=u+e$

Where A is the coefficient matrix consisting of $3 \mathrm{~N}+1$ lines: the first $3 \mathrm{~N}$ lines can be showed as $\mathrm{N}$ blocks from three equations which appear the information on the GPS position of each single EP with respect to the spot point $\mathrm{P}$, meanwhile the last equation refers to the corresponding DInSAR data, 
Citation: A. Saad, et al., Estimating Earth's Surface Deformation from GPS and DInSAR Data Integration. Australian Journal of Basic and Applied Sciences, 12(6): 1-7.

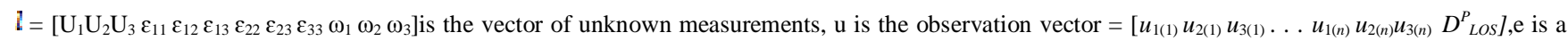
remaining vector which pattern the randomly nature of the assessment problem and $\mathrm{A}$ is the design matrix clearly derivable from the equations (1 and 3 ). Assuming regular strain field advisable method to solve the system of equations (4) is the Weighted Least Squares (WLS) to give the expression from equation (5) as a suitable formula to determine the unknown vector $\mathbb{I}$ :

$1^{\wedge}=\left(\mathrm{A}^{\mathrm{T}} \times \mathrm{W} \times \mathrm{A}\right)^{-1}\left(\mathrm{~A}^{\mathrm{T}} \times \mathrm{W} \times \mathrm{u}\right)$

Whereas $\mathrm{W}$ is the adverse of the data covariance model.

Study Area:

The study area (Figure 1) of this research covers area near Aswan High Dam and north of Lake Nasser Egypt. Aswan region is located within the stable platform of Arabio-Nubian Massif (Figure 3). The Nile River keeps track of the connection between surface roof of the granite of the Eastern Desert to the East, and the sediments of the Nubian sandstone to the West. The Nubian plain involves most of the area southwest of Aswan city and borders of the reservoir from the West (Issawi, 1969; 1978). The surface of the Nubian plain is roughly flat with a mean elevation of $200 \mathrm{~m}$. It is cut off by sandstone hills composed of resistant beds of the Nubian Formation as well as limestone hills as Gebel Marawa (274 m) (Shaker, A. et al., 2010).

The dynamic nature of African (Nubian) and Arabian plates has been implemented in many types of researches (e.g. Stern and Johnson, 2010; AbdelMonem S. Mohamed et al., 2016). The African plate moves roughly northeast direction towards the red sea in Egypt (Figure 3).

The location of Aswan seismic area is about $70 \mathrm{~km}$ southwest of the Aswan High Dam, down a western embayment of Lake Aswan. The history of Aswan High Dam belongs to 1964.

Because of the construction of the Aswan High Dam, the world's second largest reservoir has developed in southern Egypt (Awad, 1995). Aswan region is supposed to deformation due to some reasons such as the existence of Lake Nasser and the faults around it like Seiyal fault, Kalabsha fault, Kurkur fault, and Gabal El-Barqa fault (Deif. A et al., 2011).

The tectonic configuration of the area near Lake Nasser is controlled by a group of faults (Sawires. A.,2015) (Figure 2):

I. The E-W streaming faults, as the Kalabsha and Seiyal Faults, which are in the west of Lake Nasser.

II. The N-S streaming faults and they were divided into subgroups:

- $\quad$ First subgroup includes three faults (Gebel El-Barqa Fault, Kurkur Fault and Khur El-Ramla Fault). The Gebel El-Barqa is a left-lateral strike-slip fault, with a total length of $110 \mathrm{~km}$. The Kurkur Fault is also a left-lateral strike-slip fault, and it is characterized by its low seismic activity if compared with the neighbor faults. The Khur El-Ramla Fault is about $36 \mathrm{~km}$ in length, and it has no direct indication of its sense of movement.

- The second Subgroup of these faults in the SW of Lake Nasser and consists mainly of two faults: the Abu Dirwa and the Ghazala Faults. Abu Dirwa Fault is a $20 \mathrm{~km}$ long left-lateral strike-slip fault and it has a very low degree of seismic activity. In addition, for the Gazelle Fault, the analysis of its geomorphic expression shows no active features, and that there are no ground cracks observed along the fault trace. Likely this fault is inactive. The fault planes of this system are nearly vertical $\left(80-85^{\circ}\right)$.

III. The third one is a fault system streaming NNE-SSW and lies to the east of Nasser's Lake. The Dabud Fault, which represents the main fault of this group, is about $36 \mathrm{~km}$ length. Geological evidences indicate reverse-slip, opposed to the tectonic setting of the area.

\section{GPS Measurements:}

The GPS data belongs to Aswan geodetic network from December $24^{\text {th, }} 2008$ to December $28^{\text {th, }} 2010$ consisting of 11 stations and covering the northern part of Lake Aswan. There are 7 stations along the western side of Lake Aswan and 4 stations along the eastern side (Figure 4). The GPS observations were made by researchers from National Research Institute of Astronomy and Geophysics (NRIAG) using Trimble receivers 4000 SSI under unified conditions, such as: the cutoff angle is 15 degrees, the sampling interval is 30 seconds and the observation time in all sessions is 72 hours at all stations for each year.

\section{DInSAR Data:}

ASAR data has been provided by the European Space Agency (ESA) for providing the required ASAR under the project Id 21729. Two Single Look Complex (SLC) images sensed in C-band $(\lambda=5.6 \mathrm{~cm})$ of ENVISAT descending orbit were used to form one differential interferogram from July $25^{\text {th }}, 2008$ to September $3^{\text {rd }}, 2010$ (with difference 770 days). The temporal coverage ASAR data is chosen such that it achieves the best time overlap with the GPS time series data.

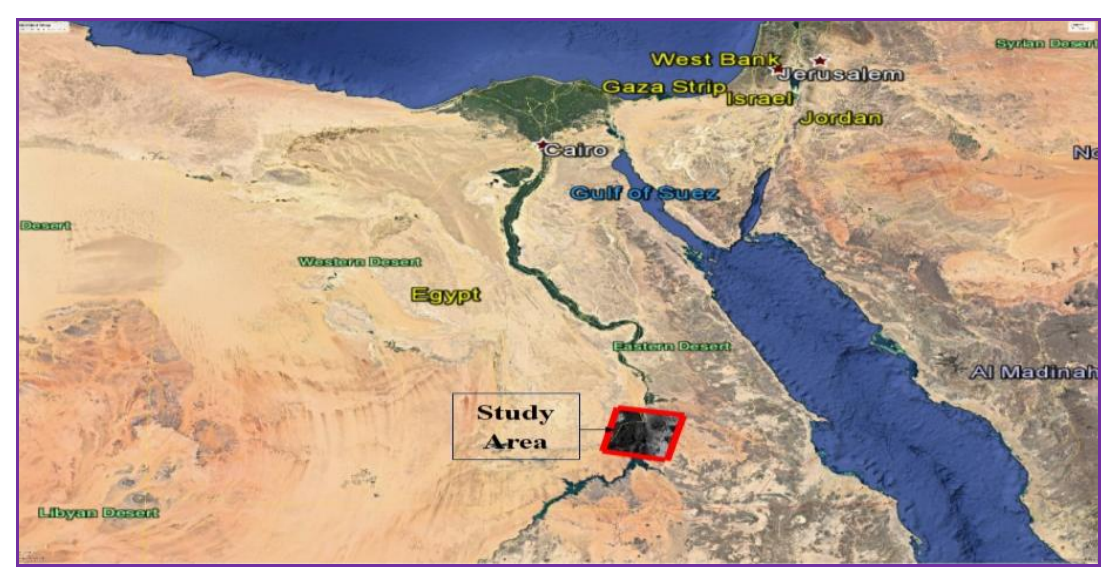

Fig. 1: Study Area.

\section{DInSAR Data Processing:}

Two pass interferometry is the method used for the generation of interferometric products (Massonnet and Feigl, 1998). This method requires two SLC images (master and slave(s)) to generate an interferogram. The slave acquisition should be registered to the master scene such that each pixel represents the same terrain in the two images (Francis I. Okeke., 2006). Once these two images were co-registered, one image may be multiplied by the complex conjugate of the other, resulting in a phase difference image, or interferogram (Gabriel et al., 1989). The resulting phase interferogram possesses phase values in the range of $-\pi$ to $+\pi$, which appear as fringes so, the effect of flat topography should be removed from the fringe image (Ravi P. Gupta., 2003). Shuttle Radar Topography Mission (SRTM 3") is used to remove the topography contribution to the phase interferogram and then, a filtering technique (Goldstein and Werner, 1998) is applied to reduce noise and to aid in the phase unwrapping process. The displacement measured by differential interferometry is not vertical, but along the radar line of sight "viewing direction" (R. Gens et al., 1996). 


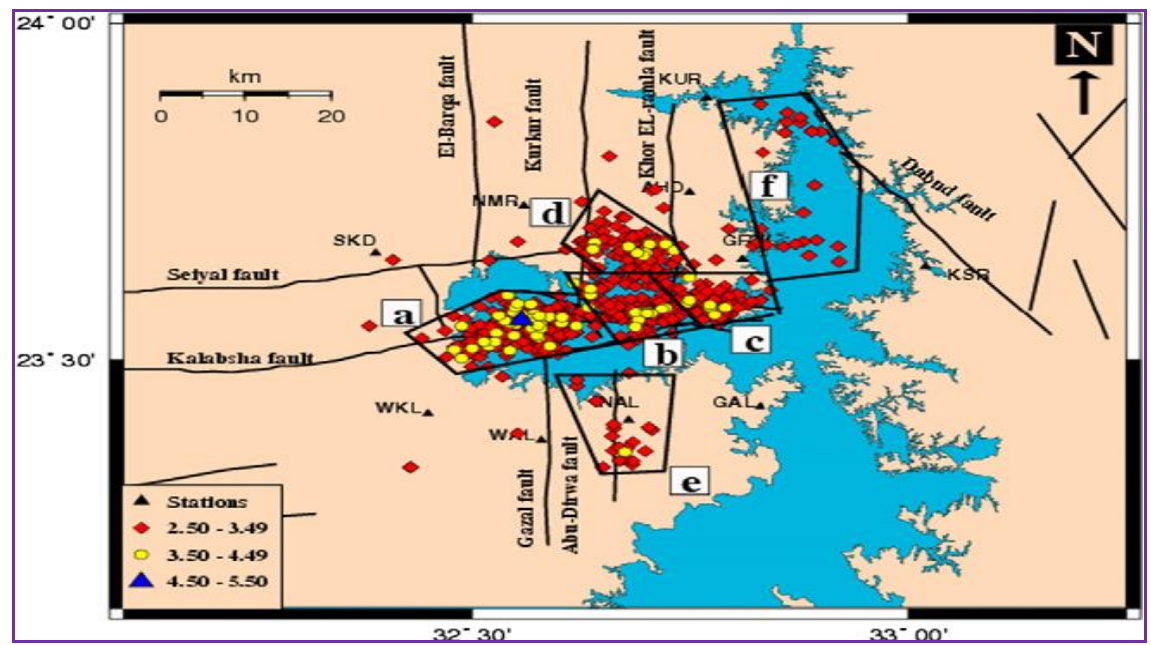

Fig. 2: Seismic sources of Aswan (after Deif et al., 2011).

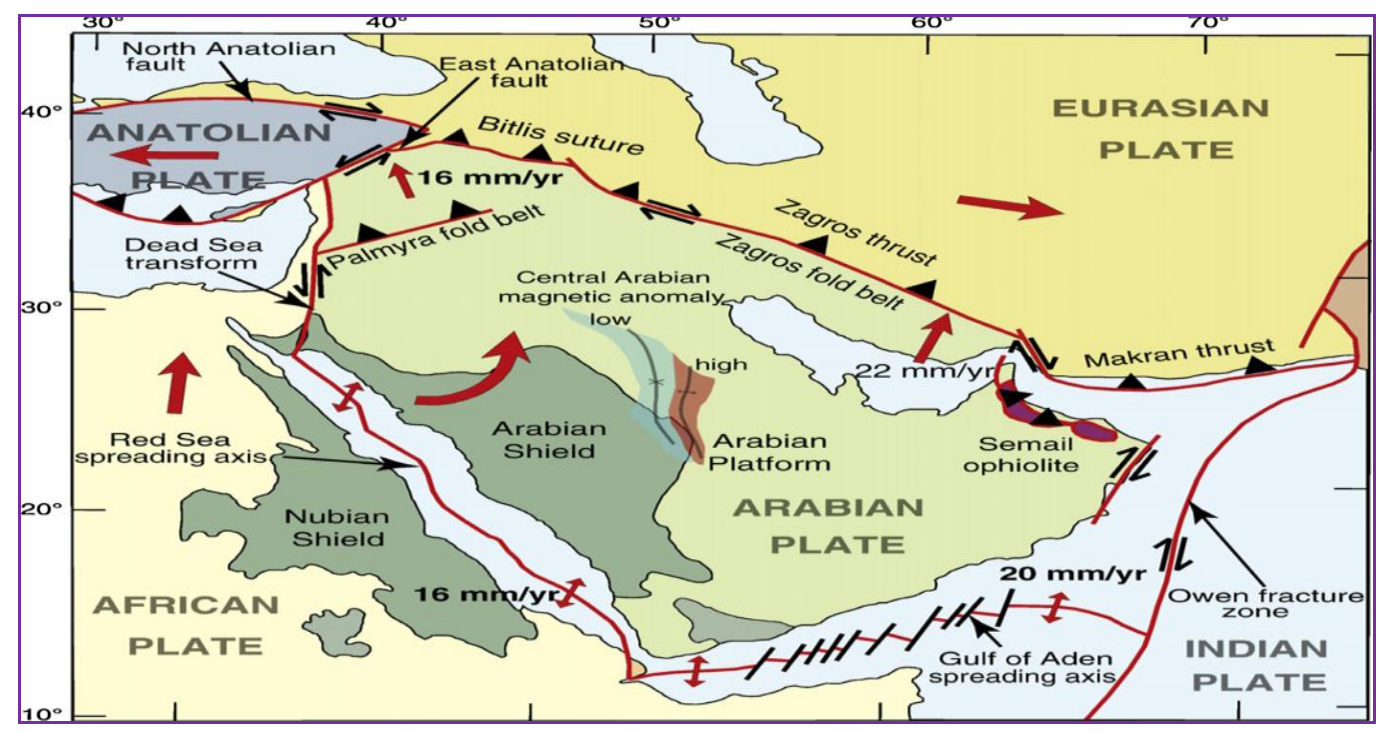

Fig. 3: Simplified map of the Arabian plate, with plate boundaries, approximate plate convergence vectors and principal geologic features (after Abdel-Monem S. Mohamed et al., 2016).

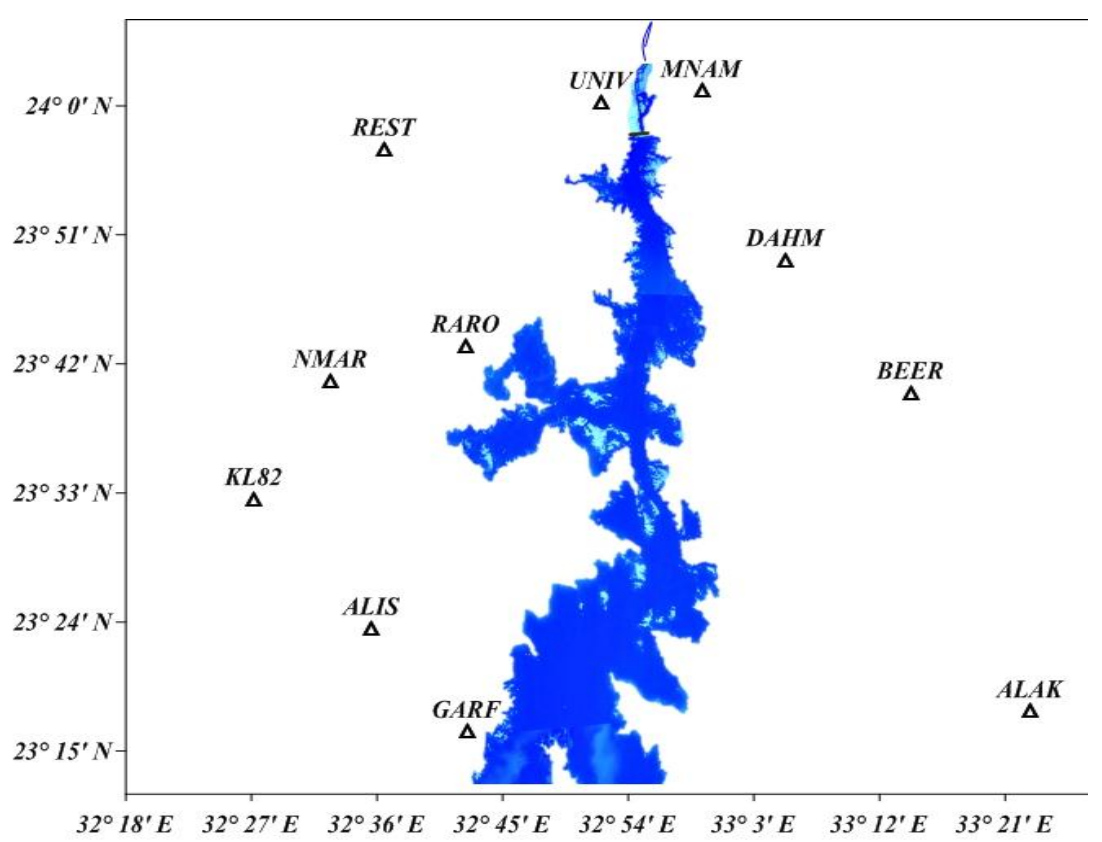

Fig. 4: Configuration of Aswan GPS Network. 
Citation: A. Saad, et al., Estimating Earth's Surface Deformation from GPS and DInSAR Data Integration. Australian Journal of Basic and Applied Sciences, 12(6): 1-7.

Results:

GPS Results:

The available GPS data were processed via Trimble Business Center (TBC) software version 3.5. The precise GPS orbits from International GNSS Services (IGS) (https://igscb.jpl.nasa.gov/components/prods cb.html) were used to compensate for orbital errors. Hopfield model along with Niell mapping functions was used to compute the tropospheric delays. The coordinates of the network stations were obtained on ITRF 2008 by solving a base station RARO with Two Permanent IGS stations Namely RAMO and DRAG in Israel after that, the coordinates of all network stations were calculated in minimally constrained adjustment to obtain the final results.

Referring to (Figure 5), the sparse GPS displacements indicate a range of horizontal motion from 24.3 to $39.3 \mathrm{~mm} / \mathrm{year}$ in approximately northeast direction. The east movement ranges between 14.9 to $37.8 \mathrm{~mm} /$ year while this range is 10.9 to $26.4 \mathrm{~mm} / \mathrm{year}$ in north direction. The vertical motion of the illustrated in (Figure 6) in which some stations were supposed to subsidence (e.g. NMAR, UNIV in west from Lake Nasser and BEER in the east) with a rate from -0.5 to -2.5 $\mathrm{mm} /$ year and other stations do the opposite with rates from 0 to $8.5 \mathrm{~mm} /$ year.

From the dynamic activity of African and Arabian plates (Figure 3), Aswan area is affected by their motion as the GPS results indicated that the motion of this area is in northeast direction (Figure 5).

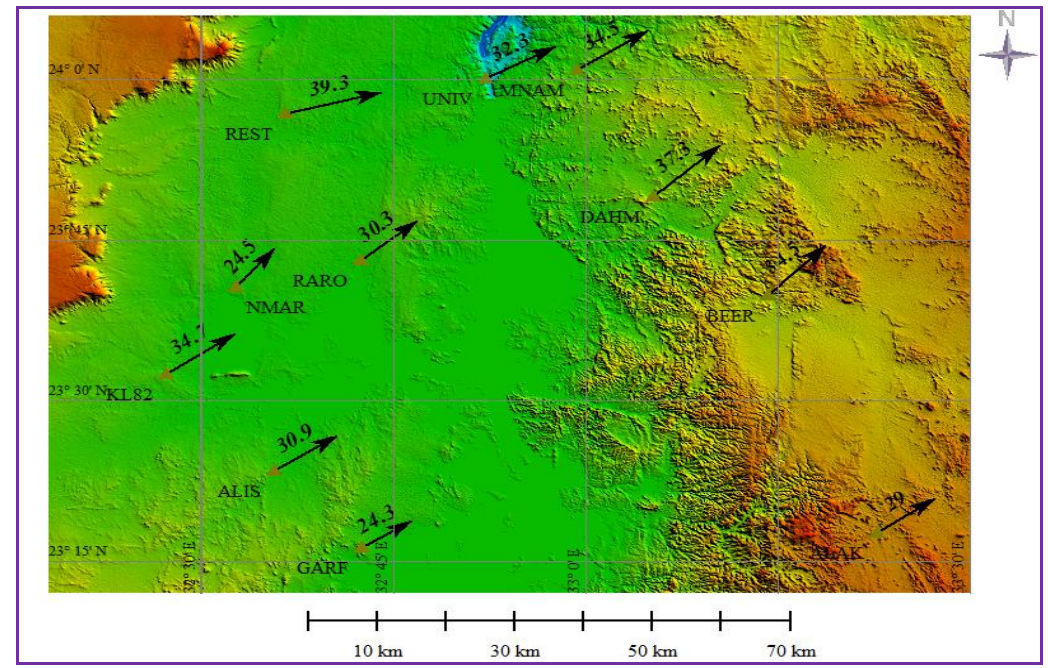

Fig. 5: Horizontal movement of Aswan GPS network using GPS data from 2008 to 2010.

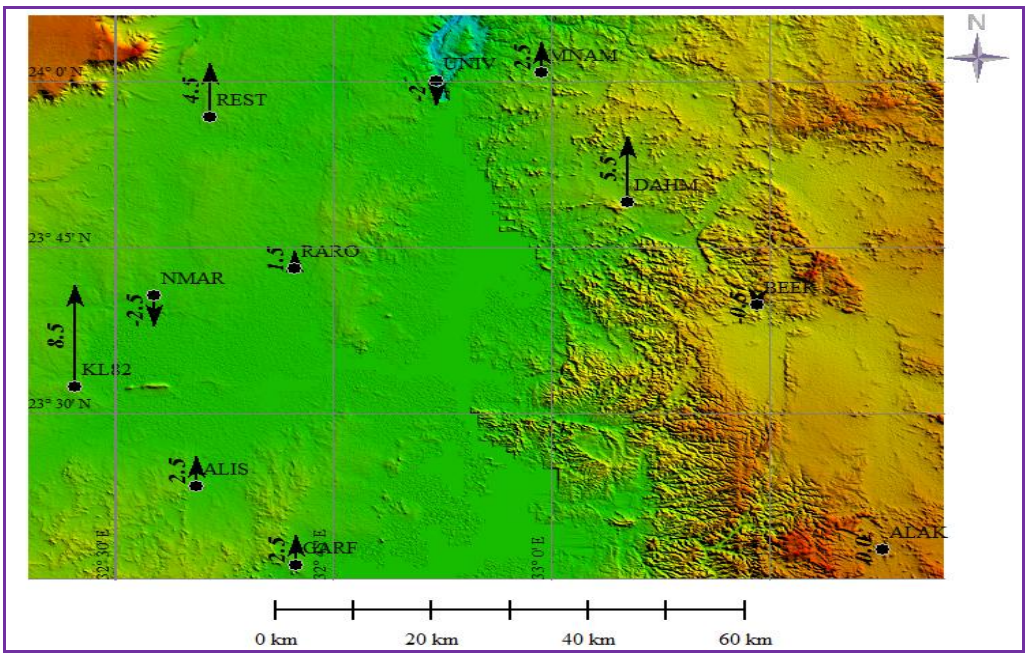

Fig. 6: Vertical movement of Aswan GPS network using GPS data from 2008 to 2010.

\section{DInSAR Results:}

A pair of Single Look Complex (SLC) images sensed along 350 ENVISAT descending orbit track from July $25^{\text {th }}, 2008$ to September $3^{\text {rd }}$, 2010 . The configuration of DInSAR data includes a temporal baseline of 770 days and perpendicular baseline of $164.65 \mathrm{~m}$ with $55.90 \mathrm{~m}$ as height ambiguity. DORIS_VOR orbits (ftp://envorb-ftp-ds.eo.esa.int/) were used to compensate for orbital errors and phase interferogram was unwrapped via SNAPHU by (Chen and Zebker, 2000) standing for Statistical-cost, Network-flow Algorithm for Phase Unwrapping (https://web.stanford.edu/group/radar/softwareandlinks/sw/snaphu/).

A Line of Sight (LOS) displacement map was obtained from the unwrapped phase interferogram (Figure 7) in which positive values indicate the displacement is towards the satellite and vice versa. The displacement vector ranges between 0 to $5 \mathrm{~cm}$. One cycle of displacement equals $28 \mathrm{~mm}$ (half the RADAR wavelength) where ASAR C-band wavelength is $5.60 \mathrm{~cm}$.

DInSAR and GPS Integration Results:

To make the two datasets temporally consistent, DInSAR LOS displacements were scaled to the time coverage of GPS data.

SISTEM integration algorithm is based on weighted least squares approach so, the weights of observations were computed from their variance covariance matrix deduced from their processing. The system of equations was solved for twelve unknowns (The 3 D Displacements maps (U1, U2 and U3), The Normal Strains $(\varepsilon 11, \varepsilon 22$ and $\varepsilon 33)$, The Shear strains $(\varepsilon 12, \varepsilon 13$ and $\varepsilon 23)$ and The Rotation tensor elements $(\omega 1, \omega 2$ and $\omega 3))$. The results are 12 maps $($ Figure 8$)$ representing the named unknowns providing a complete description of the deformation in the area with their relative standard deviations (Figure 9). For the 
Citation: A. Saad, et al., Estimating Earth's Surface Deformation from GPS and DInSAR Data Integration. Australian Journal of Basic and Applied Sciences, 12(6): 1-7.

vertical movement, some stations (e.g. ALIS, KL82, RARO and REST) were supposed to subsidence from 12.5 to 26.8 mm while others rise by a mean from $30 \pm$ $4.4 \mathrm{~mm}$. on the other hand, the related mean east and north movements of $54.8 \pm 27.5$ and $45.2 \pm 11.9 \mathrm{~mm}$ respectively.

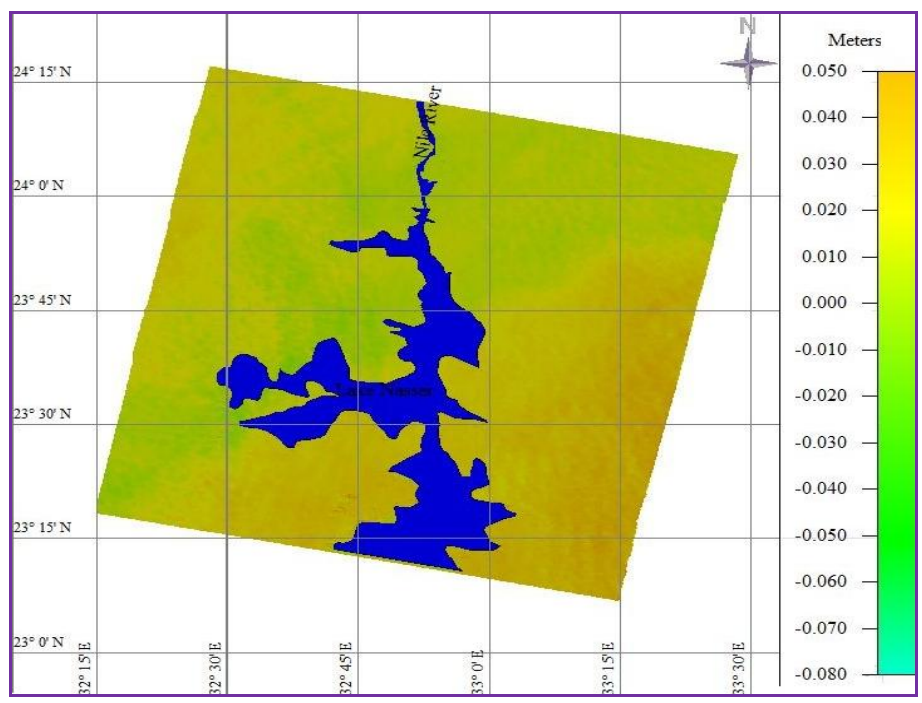

Fig. 7: Three dimensional LOS displacements of Aswan using DInSAR data from 2008 to 2010.

These results were validated by three permanent stations (Table 1) and the mean differences were 21, 15.3 and $6.7 \mathrm{~mm}$ in East, North and vertical directions.

One of the advantages of SISTEM algorithm is that it provides the complete the strain tensor information. The volumetric dilation, the maximum shear strains (Figure 10) and the differential rotational magnitudes were computed from the integration results according to the following relations (Vaníček et al., 2006):

The dilation is given by

$$
\forall n=2,3: " \sigma=\frac{1}{n} \sum_{i=1}^{n} \sigma_{i}
$$

$\forall \sigma=\sigma n_{\sigma}=$

Where, $\mathrm{n}$ is the dimensionality of the system.

The differential rotation magnitude $(\Omega)$

$\Omega^{2}=\omega_{2,2}^{2}+\omega_{2, x}^{2}+\omega_{2, x}^{2}$

And the maximum shear strain equals:

$M=\lambda_{\max }-\lambda_{\min }$

Where, $\lambda_{\max }$ and $\lambda_{\min }$ are the biggest and the youngest eigenvalues of the strain tensor matrix.

The computations show that the area is supposed to tensional dilation with a mean shear strain of 0.12 and average differential rotation 0.05 (Figure 10).

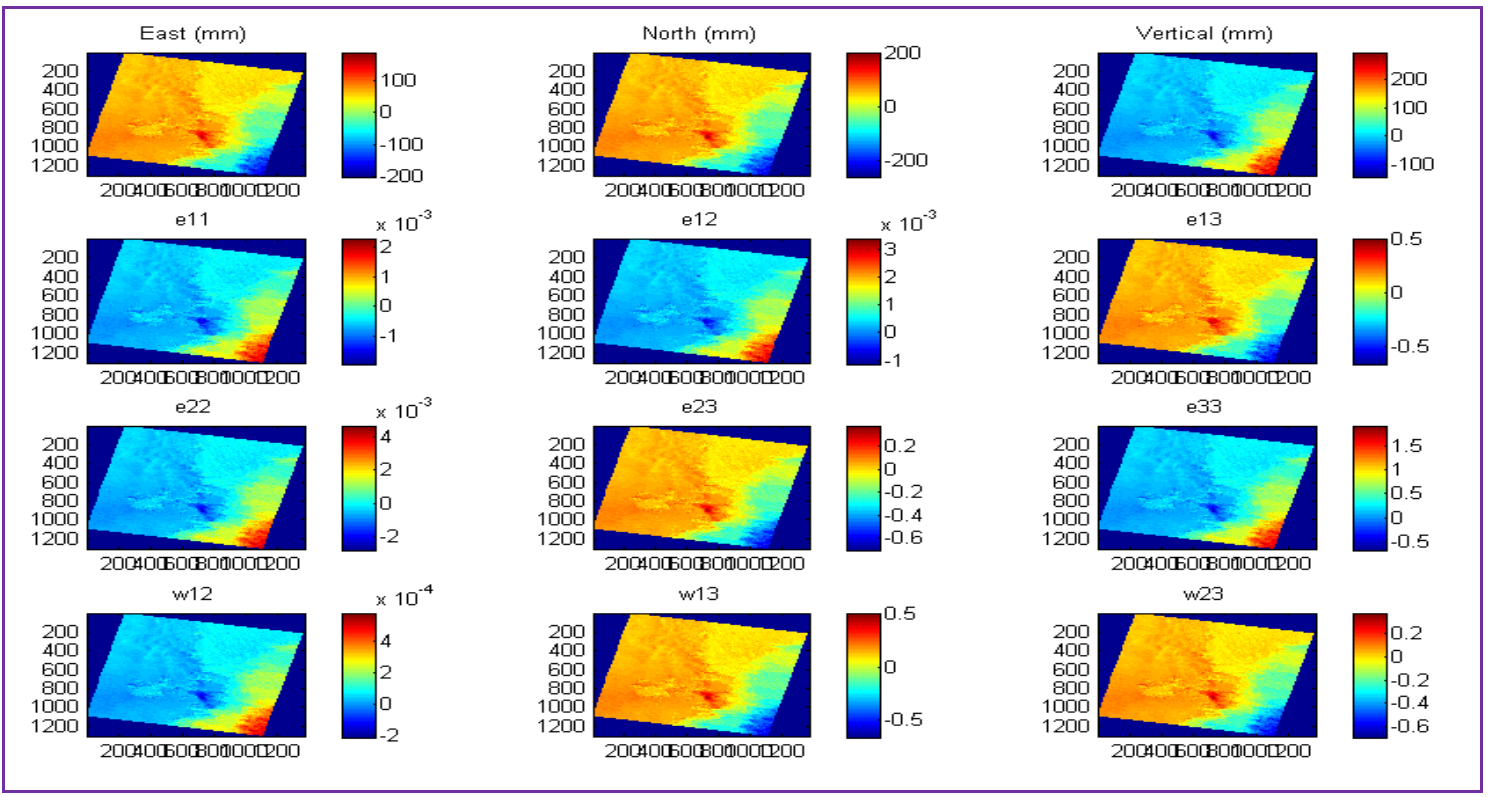

Fig. 8: Integration Results from 2008 to 2010. (First row three dimensional movements, second row the principal Strains, the next is the shear strains and the last row is rotation tensor components). 
Citation: A. Saad, et al., Estimating Earth's Surface Deformation from GPS and DInSAR Data Integration. Australian Journal of Basic and Applied Sciences, 12(6): 1-7.

Table 1: Absolute Differences between three dimensional displacements before and after integration.

\begin{tabular}{|l|l|l|l|}
\hline Station & Delta East & Delta North & Delta Vertical \\
\hline GARF & 12.6 & 14.5 & 2.2 \\
\hline MNAM & 7.5 & 3.5 & 6.9 \\
\hline NMAR & 43.0 & 27.9 & 10.8 \\
\hline Mean & 21.0 & 15.3 & 6.7 \\
\hline Maximum & 43.0 & 27.9 & 10.8 \\
\hline Minimum & 7.5 & 3.5 & 2.2 \\
\hline
\end{tabular}

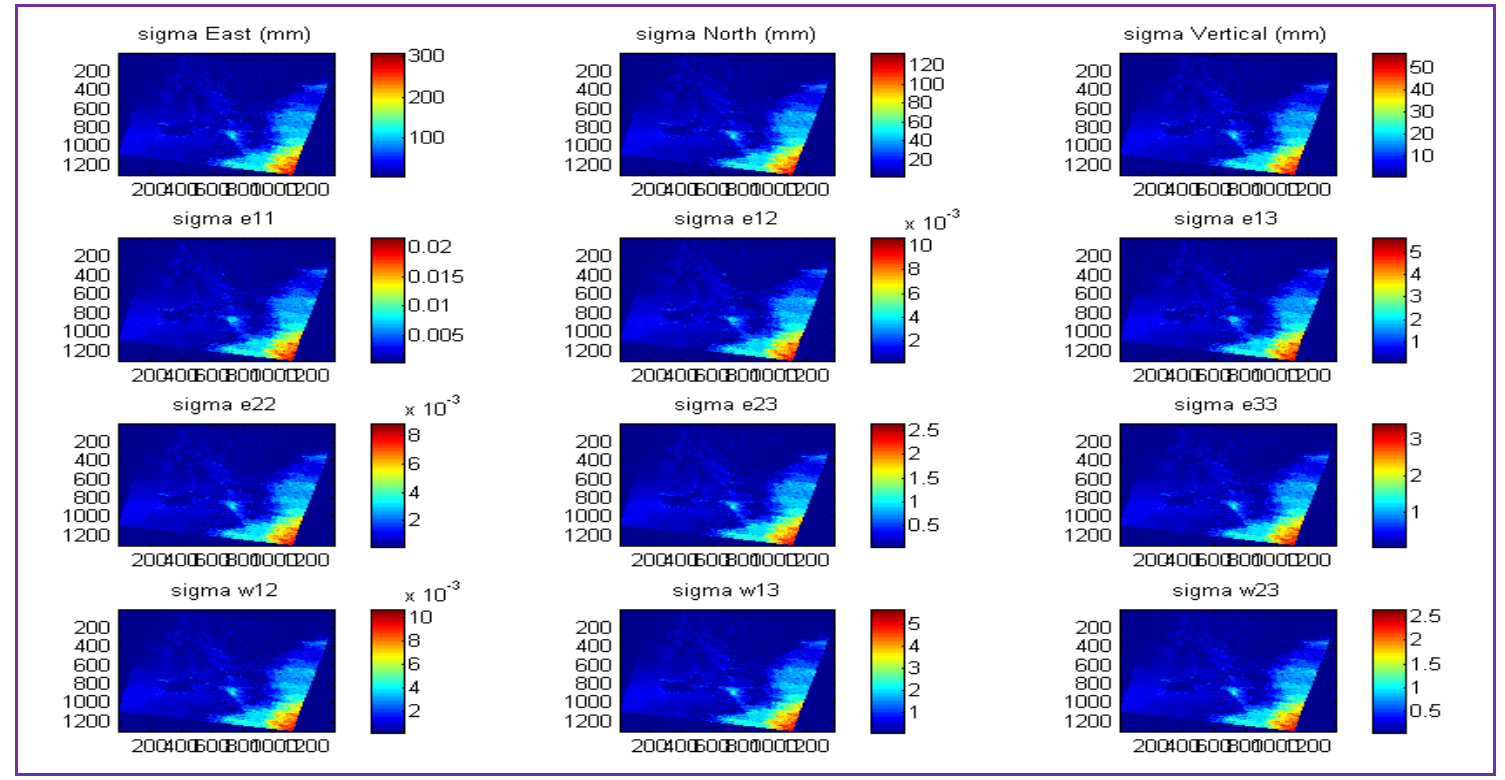

Fig. 9: Relative RMSEs of Integration Results.

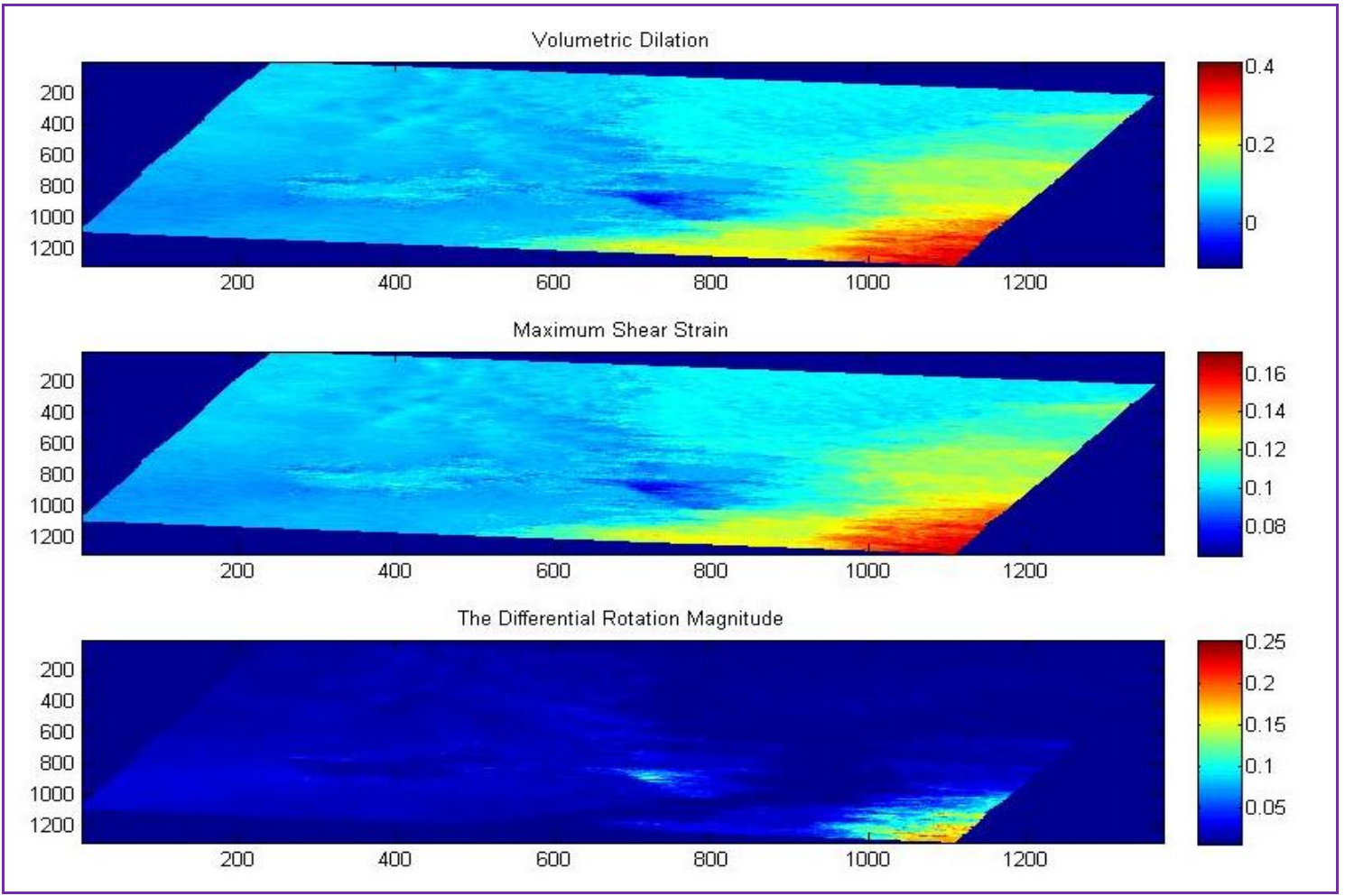

Fig. 10: Strain invariants. 
Citation: A. Saad, et al., Estimating Earth's Surface Deformation from GPS and DInSAR Data Integration. Australian Journal of Basic and Applied Sciences, 12(6): $1-7$.

\section{Conclusions:}

The location of Aswan region in the Arabio-Nubian plates and the existence of a group of faults along with one of the largest artificial water budgets - Lake Nasser - made the area supposed to deformation with time. A GPS network has been established to periodically monitor the dynamic of the area.

GPS measurements of Aswan geodetic network and ENVISAT ASAR SLC image data are used simultaneously to investigate the crustal movement in Aswan - South of Egypt in the period from 2008 to 2010 using SISTEM algorithm for the process of data integration. The results of the integration turned out the following:

- The average annual rates of displacement over the area are $30 \pm 4.4 \mathrm{~mm}, 54.8 \pm 27.5,45.2 \pm 11.9$ mm in East, North and vertical directions respectively.

- The integration results are validated by three permanent GPS stations in each epoch and the validation differences were $21,15.3$ and 6.7 mm in E, $\mathrm{N}$ and vertical directions respectively.

- The effect of African and Arabian plates makes the area to move in northeast direction.

- The area is supposed to tension due to the existence of seismic faults and the huge water artificial budget in the Lake Nasser.

Recommendations:

- $\quad$ Ascending and descending SAR data should be used for better results.

- $\quad$ Use different geodetic data (e.g. leveling) and SAR data with different viewing geometry.

\section{REFERENCES}

Abdel-Monem, S. Mohamed, Ali M. Radwan, Mohamed Sharf, Zakaria Hamimi, Esraa E. Hegazy, Nadia Abou Aly, Mahmoud Gomaa, 2016. Evaluation of the deformation parameters of the northern part of Egypt using Global Navigation Satellite System (GNSS), NRIAG Journal of Astronomy and Geophysics, 5(1): 65-75, ISSN 2090-9977, https://doi.org/10.1016/j.nrjag.2016.01.001. 548

Deif, A., H. Hamed, H.A. Ibrahim, K. Abou Elenean and E. El-Amin, 2011. Seismic hazard assessment in Aswan, Egypt. J. Geophys. Eng., 8(2011): 531-

Chen, C.W. and H.A. Zebker, 2000. "Network approaches to two-dimensional phase unwrapping: intractability and two new algorithms," Journal of the Optical Society of America A, 17: 401-414.

Ferretti, A., C. Prati and F. Rocca, 2001. Permanent scatterers in SAR Interferometry. IEEE Transactions on Geoscience and Remote Sensing, 39(1): 8-20.

Francis I. Okeke, 2006. "InSAR Operational and Processing Steps for DEM Generation Promoting Land Administration and Good Governance" 5th FIG Regional Conference Accra, Ghana, March 8-11.

Gabriel, A.K., R.M. Goldstein and H.A. Zebker, 1989. Mapping small elevation changes over large areas: Differential radar interferometry, J. Geophys. Res.,94(B7): 9183-9191, doi:10.1029/JB094iB07p09183.

Goldstein, R.M. and C.L. Werner, 1998. Radar interferogram filtering for geophysical applications. Geophysical Research Letters 25: doi: 10.1029/1998GL900033. issn: 0094-8276.

Guglielmino, F., G. Nunnari, G. Puglisi, A. Spata, 2011. Simultaneous and Integrated Strain Tensor Estimation from geodetic and satellite deformation Measurements (SISTEM) to obtain three-dimensional displacements maps. IEEE Transactions on Geoscience and Remote Sensing, 49: 1815-1826. DOI 10.1109/TGRS.2010.2103078.

Issawi, B., 1969. The Geology of Kurkur-Dungul Area. General Egyptian Organization for Geological Research and Mining; Geological Survey, 46: 101.

Cairo, Egypt.

Issawi, B., 1978. Geology of Nubia West Area, Western Desert. Annals of the Geological Survey of Egypt. vol. B, pp.237-253.

Ravi P. Gupta, 2003. Remote sensing geology, 2nd edition. Springer, Heidelberg, pp: 655.

Gens, R. and J.L. Van Genderen, 1996. Review Article SAR interferometry-issues, techniques, applications, International Journal of Remote Sensing, 17(10): 1803-1835.

Samsonov, S. and K.F. Tiampo, 2006. Analytical optimization of InSAR and GPS dataset for derivation of three-dimensional surface motion, IEEE Geoscience and Remote Sensing Letters, 3/1, doi:10.1109/LGRS.2005.858483, pp: 107-111.

Shaker, A., M. Hamed, S.M. Abdel- Monem, S. Mahmoud and A. Saad, 2010. "Crustal deformation studies in the northern part of Aswan Lake using GPS techniquell. Journal of The National Res. Inst. of Astronomy and Geophysics Ser. No. "G28" (Special Issue). Cairo, Egypt.

Sawires, R., A1-Peláez, J.A. A1-Fat-Helbary, R.E. A1-Ibrahim, H.A. A1-Hernández, M.T. García Y1 - 2015-05-20 PY - 2015 T1 - An Updated Seismic Source Model for Egypt N2 - A2 - Moustafa, Abbas BT - Earthquake Engineering - From Engineering Seismology to Optimal Seismic Design of Engineering StructuresSP - Ch. 01 UR - http://dx.doi.org/10.5772/58971 DO - 10.5772/58971 SN - PB - InTech CY - Rijeka Y2 - 2017-05-01 ER. 